\title{
Therapeutic Potential of FGF21 in Alzheimer's Disease
}

\author{
Anbang Sun ${ }^{1,2^{*}}$, Benke Xu${ }^{1}$, Xianwang Wang ${ }^{3}$, Lian Liu ${ }^{4}$, Yun He ${ }^{1}$, Zongwen Wang ${ }^{1}$, Yuncai Chen ${ }^{1,5^{*}}$ \\ ${ }^{1}$ Department of Anatomy, Medical School of Yangtze University, Jingzhou, China \\ ${ }^{2}$ The First Affiliated Hospital \& The First School of Clinical Medicine, Yangtze University, Jingzhou, China \\ ${ }^{3}$ Department of Medical Laboratory Science, Medical School of Yangtze University, Jingzhou, China \\ ${ }^{4}$ Department of Medical Function, School of Medicine, Yangtze University, Jingzhou, China \\ ${ }^{5}$ Department of Pediatrics, University of California, Irvine, CA, USA \\ Email: ^sunanbang327@163.com, xubenke@139.com, xwshine@yangtzeu.cn, zifanqie_00@126.com, \\ 408821242@qq.com, 1402763041@qq.com,yuncai_chen@hotmail.com
}

How to cite this paper: Sun, A.B., Xu, B.K., Wang, X.W., Liu, L., He, Y., Wang, Z.W. and Chen, Y.C. (2018) Therapeutic Potential of FGF21 in Alzheimer's Disease. Yangtze Medicine, 1, 1-17.

https://doi.org/10.4236/ym.2018.21001

Received: September 19, 2017

Accepted: December 10, 2017

Published: December 13, 2017

Copyright $\odot 2018$ by authors and Scientific Research Publishing Inc. This work is licensed under the Creative Commons Attribution International License (CC BY 4.0).

http://creativecommons.org/licenses/by/4.0/

\begin{abstract}
Alzheimer's disease (AD) is the most common form of dementia which mostly affects persons younger than 65 years old. Mounting findings showed that amyloid- $\beta(\mathrm{A} \beta)$ peptides, oxidative stress, neuroinflammation and insulin resistance may play central role in the pathogenesis of AD. There are very many methods to slow it through affecting these aforementioned factors. However, more efficient prevention of the progression of $\mathrm{AD}$ is still ambiguous. Fibroblast growth factor 21 (FGF21) is an endocrine hormone that is expressed by several organs. It increases insulin sensitivity and regulates lipid metabolism and energy homeostasis. Emerging evidence demonstrates that FGF21 has potential effects in the brain involving metabolic regulation, neuroprotection and cognition. Hence, we hypothesize that FGF21 may be a protective factor in $\mathrm{AD}$ by attenuating $\mathrm{A} \beta$ generation, inflammation, oxidative stress, and insulin resistance. Our hypothesis will shed new light on the understanding of pathogenesis of $\mathrm{AD}$ and help to find a new way to prevent the genesis and progress of $\mathrm{AD}$.
\end{abstract}

\section{Keywords}

FGF21, Alzheimer' Disease, Amyloid- $\beta$ (A $\beta$ ), Oxidative Stress, Inflammation, Insulin Resistance

\section{Introduction}

Alzheimer's disease (AD) is an insidious, progressive and fatal neurodegenerative disorder manifested by cognitive and memory deterioration, progressive 
impairment of daily life activities, and as well as a variety of neuropsychiatric symptoms and behavioral disturbances [1]. It is the most common form of dementia, with an estimated 5.2 million people diagnosed in the United States in 2013, of which approximately 200,000 individuals are younger than 65 [1] and $50 \%$ of people over 85 years old are affected by various degrees of $\mathrm{AD}$ [2]. There are more than 47 million people living with dementia worldwide in 2016, and the total estimated worldwide cost of dementia is more than 818 billion USD. It will become a trillion dollar disease by 2018 [3]. By 2050, the distribution of dementia cases is 67.2 million in Asia (51.5\% of total), 15.8 million in Africa (12\%), 29.9 in Americas (22.7\%) and 18.6 in Europe (14.2\%), (Table 1). Nearly $68 \%$ of all people living with dementia will live in low and middle income countries [4]. The etiology and pathogenesis of $\mathrm{AD}$ is complicated, but currently known pathological hallmarks of $\mathrm{AD}$ include the presence of neuritic plaques, neurofibrillary tangles, synaptic loss, ultimately neuronal death [5] [6] [7] [8] [9]. Methods to block the progression of the disease and prevent neuronal loss or even cure it are still ambiguous.

\section{Pathogenesis of Alzheimer's Disease}

\subsection{Amyloid- $\beta(\mathrm{A} \beta)$ Peptides}

Mounting evidence showed that amyloid- $\beta(\mathrm{A} \beta)$ peptides play a central role in the pathogenesis of $\mathrm{AD}$. The initial "amyloid cascade" hypothesis suggested that $\mathrm{A} \beta$ peptides drive the neuropathological cascade responses leading to dementia [10]. The revised amyloid cascade hypothesis suggested that soluble $\mathrm{A} \beta$ oligomers initiate the pathological cascade of AD leading to synaptic dysfunction, neuronal cell death, and dementia [11]. Moreover, transgenic mice with overexpression of the human amyloid precursor protein (APP-tg mice) have learning and memory deficits, as well as neuritic plaques similar to those seen in humans with $\mathrm{AD}$ [12]. In view of this, several immunization programs have successfully cleared the amyloid in APP-tg mice [13] [14]. However, the immunization programs attempted to clear $\mathrm{AD}$ patients brain amyloid through monoclonal antibodies, AN1792 [15], Solanezumab (LY2062430) and Bapineuzumab [16] [17], were terminated because of adverse effects 14 and lack of clinical treatment effect [16] [17]. The results of concurrent neuropsychological tests and magnetic resonance imaging (MRI) tests were surprising and disappointing, the brain

Table 1. People living with dementia around the world (million).

\begin{tabular}{cccc}
\hline Continent & 2015 & 2030 & 2050 \\
\hline Americas & $9.4(20.1 \%)$ & $15.8(21.2 \%)$ & $29.9(22.7 \%)$ \\
Europe & $10.5(22.5 \%)$ & $13.4(17.9 \%)$ & $18.6(14.2 \%)$ \\
Asia & $22.9(48.9 \%)$ & $38.5(51.5 \%)$ & $67.2(51.1 \%)$ \\
Africa & $4.0(8.5 \%)$ & $7.0(9.4 \%)$ & $15.8(12 \%)$ \\
World & 46.8 & 74.7 & 131.5 \\
\hline
\end{tabular}




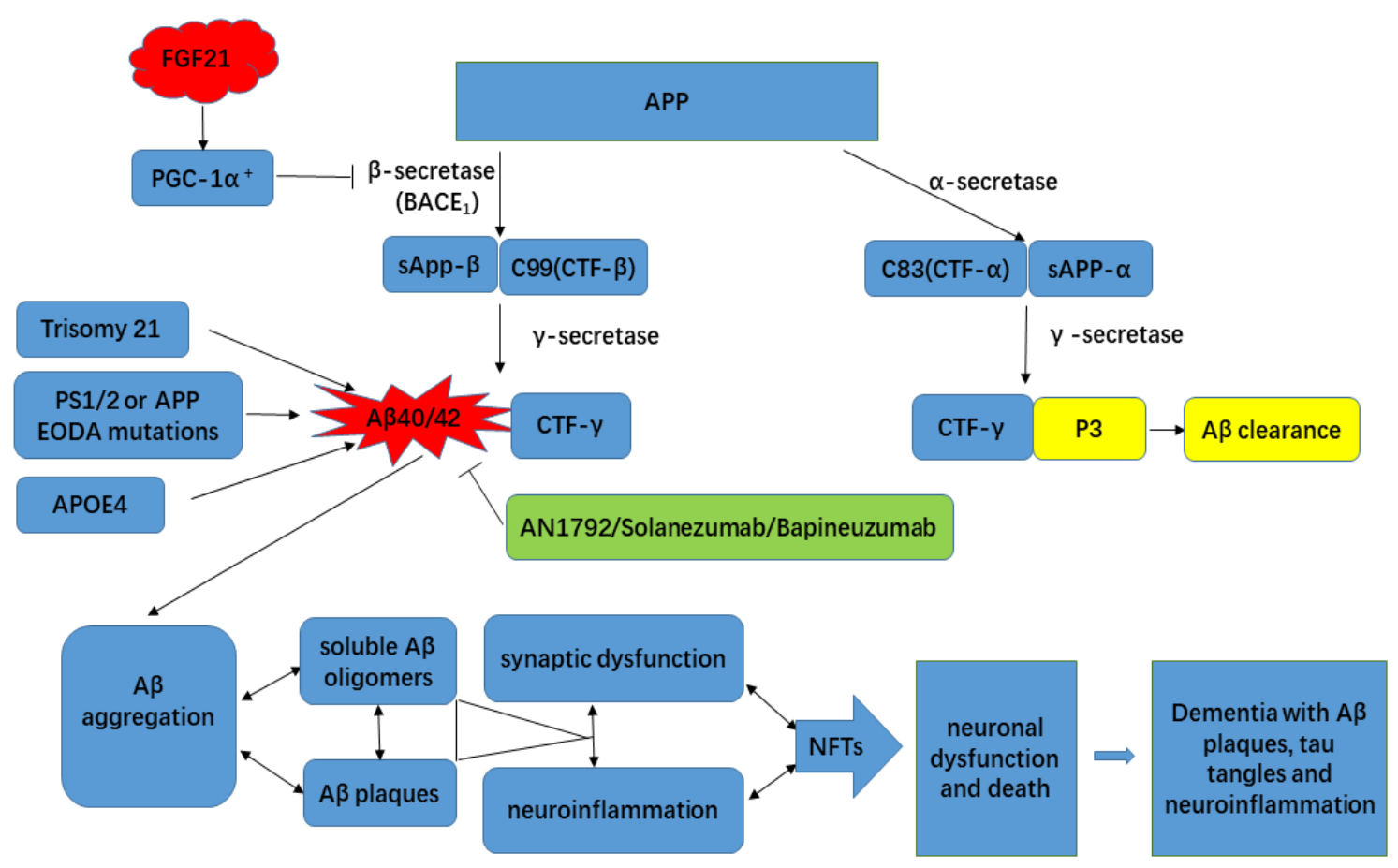

Figure 1. The potential mechanisms of $\mathrm{A} \beta$ in $\mathrm{AD}$ and the potential targets of FGF21. 1) $\mathrm{A} \beta$ derives from the amyloid precursor protein (APP), which is cleaved by $\beta$ secretase $\left(\mathrm{BACE}_{1}\right)$ and $\gamma$ secretase to yield $\mathrm{A} \beta$. The $\mathrm{A} \beta_{40}$ form is the more common isoform, but $\mathrm{A} \beta_{42}$ is the more fibrillogenic and is thus associated with disease states. It is generally believed that $\mathrm{A} \beta$ oligomers are the most toxic. It leads to synaptic dysfunction, neuroinflammation, neurofibrillary tangles, then causes neuronal dysfunction and death, ultimately result in learning and memory deficits which displayed by AD. 2) Most of autosomal dominant familial AD can be attributed to mutations in one of three genes: those encoding APP and presenilins 1 and 2 (PS1/2), while the apolipoprotein E4 (APOE4) is the major genetic risk factor for sporadic AD. People with trisomy 21 (Down Syndrome) almost universally exhibit at least the earliest symptoms of $\mathrm{AD}$ by 40 years of age. All these factors can lead to $\mathrm{A} \beta$ buildup, $\mathrm{A} \beta$ aggregation, and the sequential changes and symptoms we mentioned above. 3) There are some immunization programs attempted to clear AD patients brain amyloid through monoclonal antibodies, AN1792, Solanezumab (LY2062430) and Bapineuzumab, but they were terminated because of adverse effects and lack of clinical treatment effect. 4) FGF21 can activate peroxisome proliferator-activated receptor $\gamma$ coactivator- $1 \alpha$ (PGC- $1 \alpha$ ), then decrease $\mathrm{A} \beta$ generation by reducing BACE1 transcription.

atrophy in immunized patients was worse than that of placebo-controlled patients [18]. These findings suggested that amyloid deposition is not the only one pathogenic cause of $\mathrm{AD}$ (Figure 1).

\subsection{Oxidative Stress}

Other research indicated that oxidative stress may be involved in the pathogenesis of AD. Further study showed that oxidative stress markedly elevated in preclinical $\mathrm{AD}$ patients and amnestic mild cognitive impairment (aMCI) patients [19] [20]. The mechanism may be that the oxidative stress leads to membrane damage, cytoskeleton alterations [21] and destroy the synaptic homeostasis in the hippocampus early in the $\mathrm{AD}$ process and ultimately speeding up the progression of $\mathrm{AD}$ [19]. Growing evidence indicates that many oxidative markers are increased in the $\mathrm{AD}$ brain, including protein oxidation [22], lipid peroxida- 
tion [23], and nucleic acid oxidation [21]. Reactive oxygen species (ROS), which are cytotoxic byproducts of oxygen metabolism, are accumulated during aging, hyperglycemia, hypoxic insults and inflammation [24]. In the AD brain, these may induce synaptic loss and eventually promote neurofibrillary tangles and neuritic plaques formation [25]. Moreover, there is a positive feedback loop between oxidative stress and $\mathrm{A} \beta$, which contributes to the pathologic progress of $\mathrm{AD}$ [26] [27] [28]. This is because ROS alter the expression of $\beta$-APP cleaving enzyme $\left(\mathrm{BACE}_{1}\right)$, the rate-limiting enzyme of $\mathrm{AD}$ [29] [30], and Presenilins1 (PS1), the catalytic submit of the $\gamma$-secretase [26], thereby promoting A $\beta$ production in $\mathrm{AD}$. Meanwhile, $\mathrm{A} \beta$ induces oxidative stress and the generation of $\mathrm{HNE}$, which is a neurotoxic lipid peroxidation product and associated with $\mathrm{A} \beta$ pathology in $\mathrm{AD}$ [26]. Several studies suggested that antioxidants vitamin $\mathrm{E}$ and vitamin $\mathrm{C}$ play a role in delaying the onset of $\mathrm{AD}$ [31] [32] [33] [34]. These studies further confirmed that oxidative stress is involved in the occurrence and progression of $\mathrm{AD}$ (Figure 2).

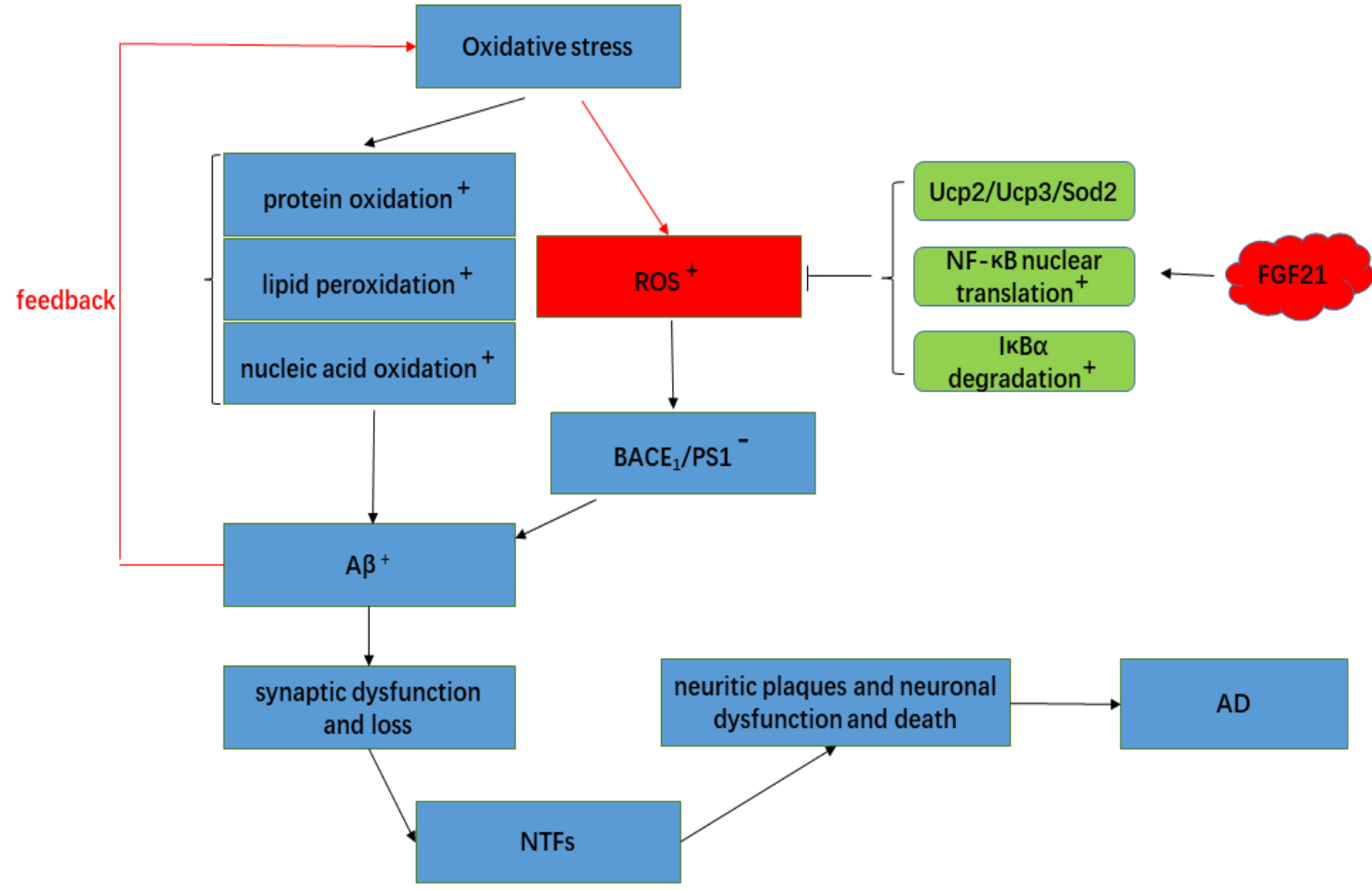

Figure 2. The potential mechanisms of oxidative stress in AD and the potential targets of FGF21. 1) Oxidative stress leads to membrane damage, cytoskeleton alterations and destroy the synaptic homeostasis in the hippocampus early in the $\mathrm{AD}$ process and ultimately speeding up the progression of $\mathrm{AD}$. During these process, there are many oxidative markers are increased in the $\mathrm{AD}$ brain, including protein oxidation, lipid peroxidation, and nucleic acid oxidation. 2) Oxidative stress can also increase the production of ROS which alter the expression of $\mathrm{BACE} 1$ and PS1, then promote the production of $\mathrm{A} \beta$ in AD. 3) There is a positive feedback loop between oxidative stress and $\mathrm{A} \beta$. All the factors mentioned above will finally lead to AD which illustrated in Figure 1. 4) FGF21 can upregulate the expression of genes encoding proteins involved in antioxidative pathways, including mitochondrial uncoupling proteins (Ucp2 and Ucp3), superoxide dismutase-2 (Sod2), reduced ROS production. It also could inhibit D-galactose-induced ROS production in a dose dependent manner, through preventing NF- $\kappa \mathrm{B}$ nuclear translation and $\mathrm{I} \kappa \mathrm{B} \alpha$ degradation. 


\subsection{Neuroinflammation}

Besides the amyloid plaques and oxidative stress, neuroinflammation in the central nervous system (CNS) also causes neuronal injury, and pro-inflammatory changes exist in early stages of the disease in AD patients, when microglial cells are activated and produce pro-inflammatory mediators [35]. Acute systemic inflammatory events with increased levels of pro-inflammatory cytokines such as tumor necrosis factor- $\alpha$ (TNF- $\alpha$ ), were associated with an increasing rate of cognitive decline in mild to severe dementia [36]. Animal models of lipopolysaccharide (LPS) induced sepsis showed CNS inflammation, neuronal death and cognitive decline [37] [38] [39]. Correspondingly, non-steroidal anti-inflammatory drugs (NSAIDs) can ameliorate behavioral and pathology deficits in AD transgenic mouse models [40] [41]. Although clinical trials have failed to reproduce the beneficial effects of NSAIDs in AD patients, they may be beneficial when administered in the early stage of the disease [42]. The anti-inflammatory effects of NSAIDs may be that NSAIDs directly bind to peroxisome proliferator-activated receptor $\gamma$ (PPAR $\gamma$ ) [42], which expressed in human brain [43] and inhibited microglial activation and the expression of a wide range of proinflammatory genes [42] [44] [45], and activate its transcriptional regulatory activities [42]. Other anti-inflammatory drugs such as trifusal showed a significant low rate of conversion to dementia in clinical trials with mild cognitive impairment patients [37] [46]. The diversity of effects may depend on the drug, because different antiinflammatory drugs may have different molecular targets. And anti-TNF $\alpha$ treatment with the antibody against $\operatorname{TNF} \alpha$, infliximab, reduced $\mathrm{A} \beta$ and tau phosphorylation in transgenic mice [41]. In addition, the TNF $\alpha$ inhibitor thalidomide can decrease the activation of both astrocytes and microglia, $\mathrm{A} \beta$ load, plaque formation and tau phosphorylation [41] (Figure 3). Further studies assessing the potential for targeting these specific inflammatory processes are needed to elucidate more effective treatments and provide a clearer understanding of the complexities of inflammatory signaling in $\mathrm{AD}$ [41].

\subsection{Insulin Resistance}

Accumulating evidence also suggests that insulin resistance acts as a known risk factor for $\mathrm{AD}$ [2] [47]. Brain insulin signaling plays a critical role in the regulation of food intake, body weight, reproduction, and learning and memory [48] [49]. Defective insulin signaling is associated with decreased cognitive ability and the development of dementia and $\mathrm{AD}$ [2] [50]. Insulin resistance, induced by peripheral metabolic syndrome, impairs the insulin signaling in the brain, which mainly impacts the PIK3/Akt pathway, then reduces $\mathrm{A} \beta$ and tau phosphorylation by inhibiting the activation of glycogen synthase kinase 3- $\alpha$ and $-\beta$ separately, which are the key signaling molecules downstream of Akt [51]. There is a feed-forward interaction between impaired insulin signaling and $\mathrm{A} \beta$ production, which contributes to the pathologic progress of the $\mathrm{AD}$ and cognitive decline [2] [52]. Insulin resistance also can promote $\mathrm{A} \beta$ generation through altering 


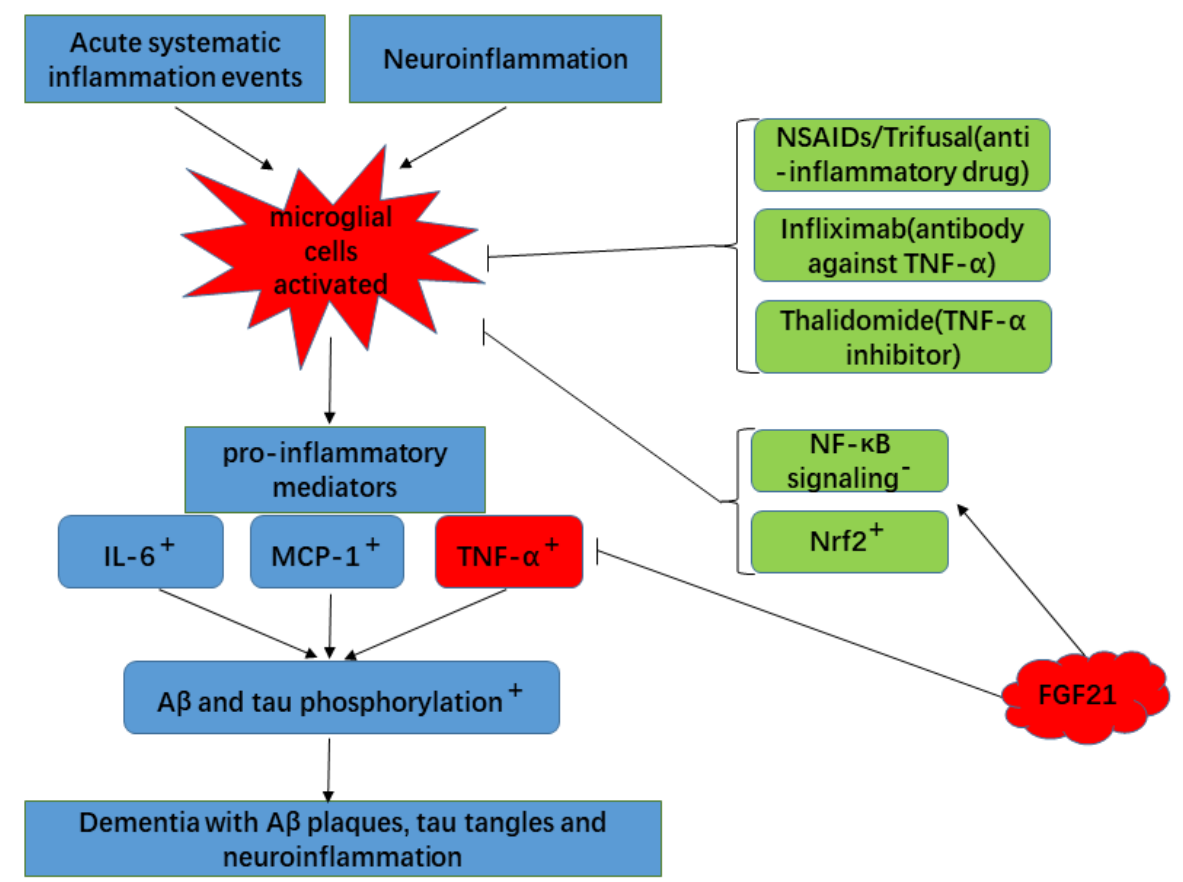

Figure 3. The potential mechanisms of neuroinflammation in $\mathrm{AD}$ and the potential targets of FGF21. 1) Neuroinflammation and acute systemic inflammatory events in the CNS causes neuronal injury, then activate the microglia cells and produce pro-inflammatory factors (TNF- $\alpha$, IL-6, MCP1) exist in early stages of the disease in AD patients. The pro-inflammatory factors increase $\mathrm{A} \beta$ formation and tau phosphorylation, then lead to dementia with $\mathrm{A} \beta$ plaques and tau tangles. 2) The anti-inflammatory drugs (NSAIDs, trifusal), directly bind to PPAR $\gamma$, then inhibit microglial activation and the expression of a wide range of proinflammatory genes. Infliximab, the antibody against $\mathrm{TNF} \alpha$, can reduce $\mathrm{A} \beta$ and tau phosphorylation. Thalidomide, the TNF $\alpha$ inhibitor, can decrease the activation of both astrocytes and microglia, $\mathrm{A} \beta$ load, plaque formation and tau phosphorylation. All the factors mentioned above can improve AD through different pathways. 3) FGF21 could significantly reduce the mRNA expression level of TNF $\alpha$. It also can inhibit macrophage-mediated inflammation, by activating the nuclear transcription factor-E2-related factor 2 (Nrf2) and suppressing the NF- $\kappa$ B signaling pathway.

insulin signal transduction, increasing BACE1 and $\gamma$-secretase activities, and accumulation of autophagosomes [52] [53]. Moreover, insulin resistance causes both cerebral glucose hypometabolism and a systemic hyperinsulinemic state [49]. Brain glucose hypometabolism was found even at the preclinical stage of $A D$ [49]. Peripheral insulin resistance not only reduced cerebral glucose metabolism, but also decreased $\mathrm{A} \beta$ clearance in the CNS [47] [48]. Rosiglitazone, a ligand for peroxisome proliferator-activated receptors (PPARs), improve cognitive function by facilitating $\mathrm{A} \beta$ clearance, reducing amyloid plaques and tau phosphorylation in $\mathrm{AD}$ mouse models [2] [54] [55]. Rosiglitazone can also protect cognitive decline in MCI patients [56] [57] [58], while pioglitazone can improve cognitive deficiency and stabilize the disease in the individuals with mild $\mathrm{AD}$ [59] [60]. Treatments to enhance cerebral glucose metabolism showed improvement in cognition and AD symptomatology [61]. Collectively, insulin resistance is closely related with the pathologic process of $\mathrm{AD}$ (Figure 4). 


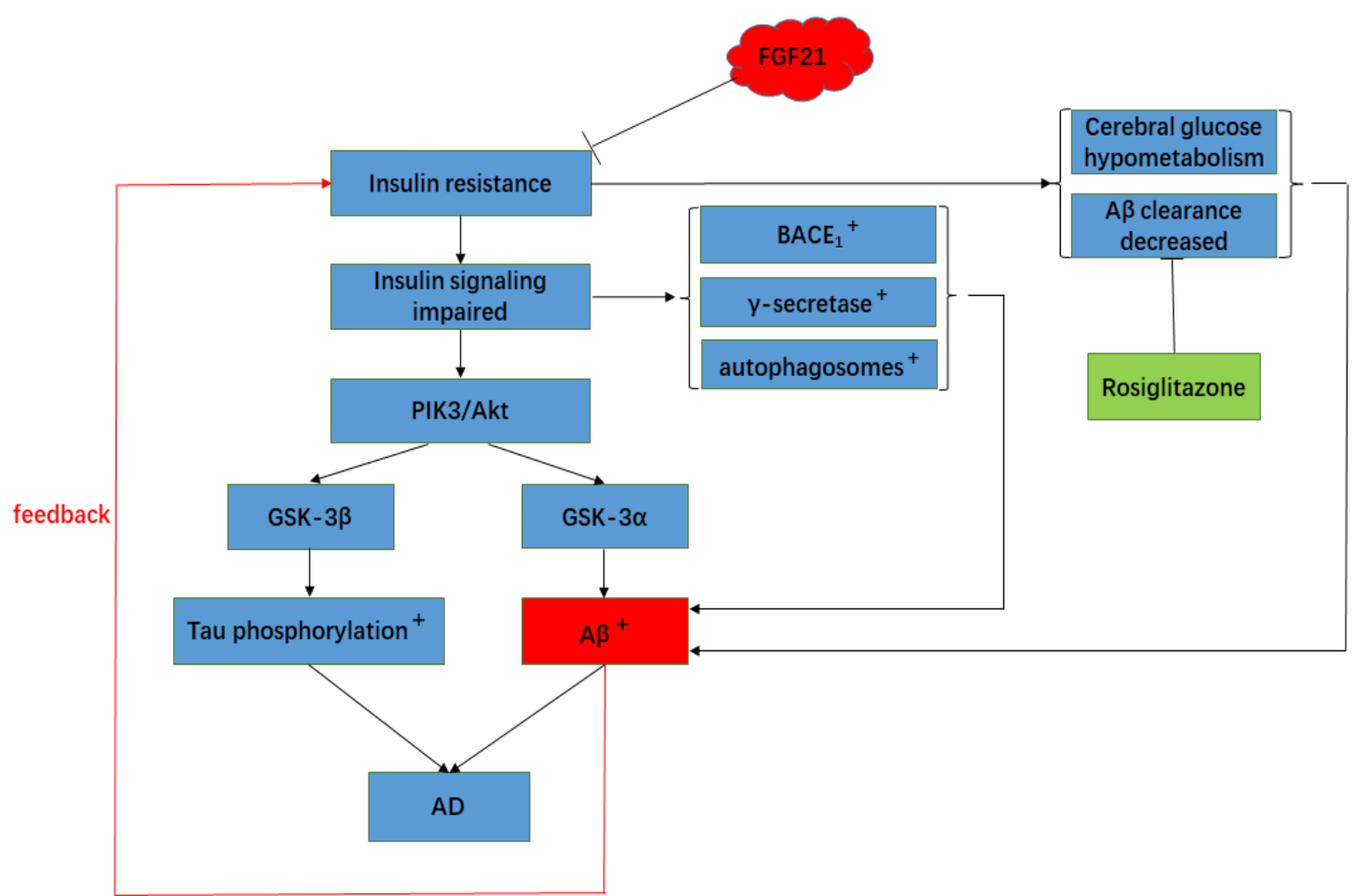

Figure 4. The potential mechanisms of insulin resistance in AD and the potential targets of FGF21. 1) Insulin resistance impairs the insulin signaling in the brain, which mainly impacts the PIK3/Akt pathway, then reduces $\mathrm{A} \beta$ and tau phosphorylation by inhibiting the activation of glycogen synthase kinase $3-\alpha$ and $-\beta$ separately. It also can promote $\mathrm{A} \beta$ generation through altering insulin signal transduction, increasing BACE1 and $\gamma$-secretase activities, and accumulation of autophagosomes. 2) There is a positive feedback loop between insulin resistance and A $\beta$. All the factors mentioned above will finally cause AD. 3) Rosiglitazone, a ligand for peroxisome proliferator-activated receptors (PPARs), improve cognitive function by facilitating $\mathrm{A} \beta$ clearance, reducing amyloid plaques and tau phosphorylation in AD. 4) FGF21 can potentially ameliorate cognition through improving insulin resistance and cerebral glucose hypometabolism.

In summary, $\mathrm{A} \beta$ peptides play a central role in the pathogenesis of $\mathrm{AD}$, while oxidative stress, neuroinflammation and insulin resistance participate in the pathogenic process of $\mathrm{AD}$.

\section{Fibroblast Growth Factor 21(FGF21) in Alzheimer's Disease}

FGF21 is one member of the FGF family. It acts as either a paracrine or an endocrine hormone, and is expressed by adipose tissue, muscles, liver, pancreas, heart, and brain [62] [63]. FGF21 can lower glucose and lipid levels, increase insulin sensitivity and regulate energy homeostasis in rodents [64]. Its activity occurs when FGF21 binds to the fibroblast growth factor receptor (FGFR) and $\beta$-klotho (KLB), a single-pass transmembrane protein [64] and an essential co-receptor for FGF21 [65] [66]. There are seven major isoforms of FGFR, including $1 \mathrm{~b}, 1 \mathrm{c}, 2 \mathrm{~b}, 2 \mathrm{c}, 3 \mathrm{~b}, 3 \mathrm{c}$ and 4 . In vivo study, FGFR1c is the primary receptor to mediate its activity [67] [68] [69]. In fact, FGF21 is expressed in several areas of the brain, including the substantia nigra, striatum, hippocampus and 
cortex [70]. It can enter the brain from blood and can also be detected in human cerebrospinal fluid [71] [72] [73]. Moreover, FGFs and KLB have been found in several brain areas [74] [75] [76]. These findings indicate that FGF21 may have potential regulating roles in the CNS.

\subsection{FGF21 and Amyloid- $\beta(A \beta)$ Peptides}

Growing evidence demonstrates that FGF21 activated peroxisome proliferatoractivated receptor $\gamma$ coactivator-1 $\alpha$ (PGC-1 $\alpha$ ) [70] [77] [78] [79] [80], which is abundantly expressed in the brain [81] [82]. The expression of PGC-1 $\alpha$ is reduced in the brain of AD patients. Exogenous human PGC-1 $\alpha$ (hPGC- $1 \alpha$ ) expressed in primary neurons from the Tg2576 mouse of $\mathrm{AD}$ decreased $\mathrm{A} \beta$ generation by reducing BACE1 transcription which was dependent on PPAR $\gamma$ [83] [84]. In accordance with this result, gene delivery of hPGC-1 $\alpha$ in the brain of transgenic APP23 mice reduced amyloid deposition, which correlated with a decrease in BACE1 expression [85]. These findings suggest that FGF21 may reduce $\mathrm{A} \beta$ generation by decreasing BACE1 expression, as illustrated in Figure 1.

\subsection{FGF21 and 0xidative Stress}

As widely known, ROS, the cytotoxic byproducts of oxygen metabolism, could induce synaptic loss, promote neurofibrillary tangles, form neuritic plaques and finally cause neuron death [24]. This plays an essential role in the pathologic progress of $\mathrm{AD}$. Recent work has shown that FGF21 participates in regulating oxidative stress [86] [87] [88]. It upregulated the expression of genes encoding proteins involved in antioxidative pathways, including mitochondrial uncoupling proteins (Ucp2 and Ucp3), superoxide dismutase-2 (Sod2), reduced ROS production in cardiomyocytes, and ameliorated cardiac tissue injury [86] [87]. In the brain of aging mice, FGF21could inhibit D-galactose-induced ROS production in a dose dependent manner [87], through preventing NF- $\kappa \mathrm{B}$ nuclear translation and $\mathrm{I} \kappa \mathrm{B} \alpha$ degradation [88]. Hence, as showed in Figure 2, FGF21 may ameliorate the oxidative stress of $\mathrm{AD}$ by enhancing the activities of SOD and reducing the production of ROS.

\subsection{FGF21 and Inflammation}

Increasing evidences demonstrated that inflammatory process play a critical role in $\mathrm{AD}$ progression [89] [90] [91]. However, FGF21 was demonstrated a modulatory role in the inflammatory processes [61] [73]. As demonstrated in Figure 3 , it acted as a positive acute phase response (APR) protein and protected mice from the challenge of LPS and sepsis [61]. The inflammatory genes such as interleukin-6 (IL-6), and monocyte chemoattractant protein-1 (MCP-1) were significantly higher in FGF21 knockout mice [86]. While in $\mathrm{db} / \mathrm{db}$ mice models, FGF21 treatment significantly reduced the mRNA expression level of TNF $\alpha$ [92]. FGF21 inhibited macrophage-mediated inflammation, by activating the nuclear transcription factor-E2-related factor 2 (Nrf2) and suppressing the NF- $\kappa$ B sig- 
naling pathway [93].

\subsection{FGF21 and Insulin Resistance}

A growing body of findings suggests that insulin resistance is closely related with the pathologic process of $\mathrm{AD}$ [2] [50] [51]. FGF21 acts as one of the metabolic regulators. It has been demonstrated as a potent regulator of glycemia, lipid metabolism and energy homeostasis [94] [95]. Recombinant FGF21 treatment can improve whole-body insulin sensitivity and reduce plasma levels of glucose and triglycerides in diabetic mice [94], while loss of endogenous FGF21 in vivo led to increased insulin resistance and pancreatic islet hyperplasia and dysfunction [95]. As presented in Figure 4, FGF21 can potentially ameliorate cognition through improving insulin resistance and cerebral glucose hypometabolism.

\section{Conclusions}

Here, we hypothesize that the FGF21 may be a protective factor in AD by attenuating $\mathrm{A} \beta$ generation, inflammation, oxidative stress, and insulin resistance.

FGF21 increased energy expenditure and insulin sensitivity in obese rats, and intracerebroventricular injection of FGF21 into rats increased metabolic rate and insulin sensitivity [96]. FGF21 also acts as a robust neuroprotective factor and a potentially new therapeutic target for CNS disorders. For example, exogenous FGF21 protein completely protected aging neurons from glutamate challenge [97]. The serumal FGF21 levels increased significantly in patients with schizophrenia [96]. It may be involved in regulating glucose metabolism in schizophrenia, with positive correlations with pyruvate, lactate, 2-oxoglutarate, and malate in the schizophrenia group [96]. On the other hand, FGF21 activated PGC-1 $\alpha$ and increased mitochondrial efficacy in human dopaminergic neurons which suggest that FGF21 could potentially play a role in dopaminergic neuron viability and in Parkinson's disease [70].

Moreover, increasing evidence indicates that FGF21 has beneficial roles on behavior and cognition. The activity of transgenic overexpression of FGF21 mice (TgFgf21) increased during light phase, but decreased during dark phase. This circadian behavior in mice can also be altered by genetically deleting KLB in the brain [75]. The locomotor activity of FGF21 transgenic mice was reduced after a 24 hours fast [98]. D-galactose-induced aging mice, which were administrated with FGF21, had preserved cognitive function. This may be related to FGF21's ability to reduce brain cell damage in hippocampus by attenuating oxidative stress, increasing anti-oxidant activity, decreasing the enhanced total cholinesterase activity in the brain and reducing the expression of pro-inflammation cytokines such as IL-6 and TNF- $\alpha$ [63] [88].

Taken together, FGF21 acts as a neuroprotective factor, performs its decreased $\mathrm{A} \beta$ generation, anti-inflammatory, anti-oxidative stress, and glucose homeostatic effects. In view of the complex pathogenesis of $A D$, we propose that FGF21 may be a protective factor in $\mathrm{AD}$ by attenuating $\mathrm{A} \beta$ generation, inflammation, oxida- 
tive stress, and insulin resistance. It may be a potential therapeutic for $\mathrm{AD}$.

\section{Acknowledgements}

The study was supported by the Yangtze Youth Fund (Grant NO.2015cqn79), the Chutian Scholars Program (2012-12) and the Yangtze Fund for Youth Teams of Science and Technology Innovation (Grant NO.2016cqt04).

\section{References}

[1] Weuve, J., Hebert, L.E., Scherr, P.A. and Evans, D.A. (2014) Deaths in the United States among Persons with Alzheimer's Disease (2010-2050). Alzheimers \& Dementia: The Journal of the Alzheimers Association, 10, e40-e46. https://doi.org/10.1016/j.jalz.2014.01.004

[2] Kim, B. and Feldman, E.L. (2015) Insulin Resistance as a Key Link for the Increased Risk of Cognitive Impairment in the Metabolic Syndrome. Experimental \& Molecular Medicine, 47, e149. https://doi.org/10.1038/emm.2015.3

[3] Herrera, A.C., Prince, M., Knapp, M., Karagiannidou, M. and Guerchet, M. (2016) World Alzheimer Report 2016. The Global Impact of Dementia. An Analysis of Prevalence, Incidence, Cost and Trends.

[4] Prince, M., Wimo, A., Guerchet, M., Ali, G.C., Wu, Y.T. and Prina, M. (2015) World Alzheimer Report 2015. The Global Impact of Dementia. An Analysis of Prevalence, Incidence, Cost and Trends.

[5] Mckeith, I.G., Galasko, D., Kosaka, K., et al. (1996) Consensus Guidelines for Clinical and Pathological Diagnosis of Dementia with Lewy Bodies (DLB): Report of the CDLB International Workshop. Neurology, 47, 1113-1124.

https://doi.org/10.1212/WNL.47.5.1113

[6] Vickers, J.C., Dickson, T.C., Adlard, P.A., Saunders, H.L., King, C.E. and Mccormack, G. (2000) The Cause of Neuronal Degeneration in Alzheimer's Disease. Progress in Neurobiology, 60, 139-165. https://doi.org/10.1016/S0301-0082(99)00023-4

[7] Jack, C.R.Jr., Dickson, D.W., Parisi, J.E., et al. (2002) Antemortem MRI Findings Correlate with Hippocampal Neuropathology in Typical Aging and Dementia. Neurology, 58, 750-757. https://doi.org/10.1212/WNL.58.5.750

[8] Bennett, D.A., Wilson, R.S., Schneider, J.A., et al. (2003) Apolipoprotein E epsilon4 allele, AD Pathology, and the Clinical Expression of Alzheimer's Disease. Neurology, 60, 246-252. https://doi.org/10.1212/01.WNL.0000042478.08543.F7

[9] Hoozemans, J.J., Veerhuis, R., Van Haastert, E.S., et al. (2005) The Unfolded Protein Response Is Activated in Alzheimer's Disease. Acta Neuropathologica, 110, 165-172. https://doi.org/10.1007/s00401-005-1038-0

[10] Hardy, J. (2002) Testing Times for the "Amyloid Cascade Hypothesis". Neurobiology Aging, 23, 1073-1074. https://doi.org/10.1016/S0197-4580(02)00042-8

[11] Mor, F. and Monsonego, A. (2006) Immunization Therapy in Alzheimer's Disease. Expert Review of Neurotherapeutics, 6, 653-659. https://doi.org/10.1586/14737175.6.5.653

[12] Mufson, E.J., Ikonomovic, M.D., Counts, S.E., et al. (2016) Molecular and Cellular Pathophysiology of Preclinical Alzheimer's Disease. Behavioural Brain Research, 311, 54-69. https://doi.org/10.1016/j.bbr.2016.05.030

[13] Qu, B., Boyer, P.J., Johnston, S.A., Hynan, L.S. and Rosenberg, R.N. (2006) Abeta42 
Gene Vaccination Reduces Brain Amyloid Plaque Burden in Transgenic Mice. The Journal of the Neurological Sciences, 244, 151-158. https://doi.org/10.1016/j.jns.2006.02.006

[14] Gilman, S., Koller, M., Black, R.S., et al. (2005) Clinical Effects of Abeta Immunization (AN1792) in Patients with $\mathrm{AD}$ in an Interrupted Trial. Neurology, 64, 1553-1562. https://doi.org/10.1212/01.WNL.0000159740.16984.3C

[15] Fox, N.C., Black, R.S., Gilman, S., et al. (2005) Effects of Abeta Immunization (AN1792) on MRI Measures of Cerebral Volume in Alzheimer Disease. Neurology, 64, 1563-1572. https://doi.org/10.1212/01.WNL.0000159743.08996.99

[16] Salloway, S., Sperling, R., Fox, N.C., et al. (2014) Two Phase 3 Trials of Bapineuzumab in Mild-to-Moderate Alzheimer's Disease. The New England Journal of Medicine, 370, 322-333. https://doi.org/10.1056/NEJMoa1304839

[17] Doody, R.S., Thomas, R.G., Farlow, M., et al. (2014) Phase 3 Trials of Solanezumab for Mild-to-Moderate Alzheimer's Disease. The New England Journal of Medicine, 370, 311-321. https://doi.org/10.1056/NEJMoa1312889

[18] Cummings, J.L. (2004) Alzheimer's Disease. The New England Journal of Medicine, 351, 56-67. https://doi.org/10.1056/NEJMra040223

[19] Esposito, E., Rotilio, D., Di Matteo, V., Di Giulio, C., Cacchio, M. and Algeri, S. (2002) A Review of Specific Dietary Antioxidants and the Effects on Biochemical Mechanisms Related to Neurodegenerative Processes. Neurobiology of Aging, 23, 719-735. https://doi.org/10.1016/S0197-4580(02)00078-7

[20] Lovell, M.A. and Markesbery, W.R. (2001) Ratio of 8-Hydroxyguanine in Intact DNA to Free 8-Hydroxyguanine Is Increased in Alzheimer Disease Ventricular Cerebrospinal Fluid. Archives of Neurology, 58, 392-396. https://doi.org/10.1001/archneur.58.3.392

[21] Perry, G., Nunomura, A., Hirai, K., Takeda, A., Aliev, G. and Smith, M.A. (2000) Oxidative Damage in Alzheimer's Disease: The Metabolic Dimension. International Journal of Developmental Neuroscience, 18, 417-421. https://doi.org/10.1016/S0736-5748(00)00006-X

[22] Smith, M.A., Richey Harris, P.L., Sayre, L.M., Beckman, J.S. and Perry, G. (1997) Widespread Peroxynitrite-Mediated Damage in Alzheimer's Disease. The Journal of Neuroscience, 17, 2653-2657.

[23] Mark, R.J., Pang, Z., Geddes, J.W., Uchida, K. and Mattson, M.P. (1997) Amyloid Beta-Peptide Impairs Glucose Transport in Hippocampal and Cortical Neurons: Involvement of Membrane Lipid Peroxidation. The Journal of Neuroscience, 17, 1046-1054.

[24] Guglielmotto, M., Giliberto, L., Tamagno, E. and Tabaton, M. (2010) Oxidative Stress Mediates the Pathogenic Effect of Different Alzheimer's Disease Risk Factors. Frontiers in Aging Neuroscience, 2, 3. https://doi.org/10.3389/neuro.24.003.2010

[25] Kern, A. and Behl, C. (2009) The Unsolved Relationship of Brain Aging and Late-Onset Alzheimer Disease. Biochimica et Biophysica Acta, 1790, 1124-1132. https://doi.org/10.1016/j.bbagen.2009.07.016

[26] Tamagno, E., Guglielmotto, M., Aragno, M., et al. (2008) Oxidative Stress Activates a Positive Feedback between the Gamma- and Beta-Secretase Cleavages of the Beta-Amyloid Precursor Protein. Journal of Neurochemistry, 104, 683-695.

[27] Butterfield, D.A., Swomley, A.M. and Sultana, R. (2013) Amyloid Beta-Peptide (1-42)-Induced Oxidative Stress in Alzheimer Disease: Importance in Disease Pathogenesis and Progression. Antioxidants \& Redox Signaling, 19, 823-835. https://doi.org/10.1089/ars.2012.5027 
[28] Tamagno, E., Guglielmotto, M., Monteleone, D. and Tabaton, M. (2012) Amyloid-Beta Production: Major Link between Oxidative Stress and BACE1. Neurotoxicity Research, 22, 208-219. https://doi.org/10.1007/s12640-011-9283-6

[29] Tan, J.L., Li, Q.X., Ciccotosto, G.D., et al. (2013) Mild Oxidative Stress Induces Redistribution of BACE1 in Non-Apoptotic Conditions and Promotes the Amyloidogenic Processing of Alzheimer's Disease Amyloid Precursor Protein. PLoS ONE, 8 , e61246. https://doi.org/10.1371/journal.pone.0061246

[30] Jiang, Y., Rigoglioso, A., Peterhoff, C.M., et al. (2016) Partial BACE1 Reduction in a Down Syndrome Mouse Model Blocks Alzheimer-Related Endosomal Anomalies and Cholinergic Neurodegeneration: Role of APP-CTF. Neurobiology of Aging, 39, 90-98. https://doi.org/10.1016/j.neurobiolaging.2015.11.013

[31] Calsolaro, V. and Edison, P. (2016) Neuroinflammation in Alzheimer's Disease: Current Evidence and Future Directions. Alzheimer's \& Dementia, 12, 719-732. https://doi.org/10.1016/j.jalz.2016.02.010

[32] Kontush, A., Mann, U., Arlt, S., et al. (2001) Influence of Vitamin E and C Supplementation on Lipoprotein Oxidation in Patients with Alzheimer's Disease. Free Radical Biology and Medicine, 31, 345-354. https://doi.org/10.1016/S0891-5849(01)00595-0

[33] Salerno-Kennedy, R. and Cashman, K.D. (2005) Relationship between Dementia and Nutrition-Related Factors and Disorders: An Overview. International Journal for Vitamin and Nutrition Research, 75, 83-95. https://doi.org/10.1024/0300-9831.75.2.83

[34] Whalley, L.J., Starr, J.M. and Deary, I.J. (2004) Diet and Dementia. Post Reproductive Health, 10, 113-117. https://doi.org/10.1258/1362180043654575

[35] Holmes, C., Cunningham, C., Zotova, E., et al. (2009) Systemic Inflammation and Disease Progression in Alzheimer Disease. Neurology, 73, 768-774. https://doi.org/10.1212/WNL.0b013e3181b6bb95

[36] Cunningham, C. (2013) Microglia and Neurodegeneration: The Role of Systemic Inflammation. Glia, 61, 71-90. https://doi.org/10.1002/glia.22350

[37] McGeer, P.L. and McGeer, E.G. (2007) NSAIDs and Alzheimer Disease: Epidemiological, Animal Model and Clinical Studies. Neurobiology of Aging, 28, 639-647. https://doi.org/10.1016/j.neurobiolaging.2006.03.013

[38] Sun, J., Zhang, S., Zhang, X., Zhang, X., Dong, H. and Qian, Y. (2015) IL-17A Is Implicated in Lipopolysaccharide-Induced Neuroinflammation and Cognitive Impairment in Aged Rats via Microglial Activation. Journal of Neuroinflammation, 12, 165. https://doi.org/10.1186/s12974-015-0394-5

[39] Zhang, X.Y., Cao, J.B., Zhang, L.M., Li, Y.F. and Mi, W.D. (2015) Deferoxamine Attenuates Lipopolysaccharide-Induced Neuroinflammation and Memory Impairment in Mice. Journal of Neuroinflammation, 12, 20. https://doi.org/10.1186/s12974-015-0238-3

[40] Craft, S. (2007) Insulin Resistance and Alzheimer's Disease Pathogenesis: Potential Mechanisms and Implications for Treatment. Current Alzheimer Research, 4, 147-152. https://doi.org/10.2174/156720507780362137

[41] Birch, A.M., Katsouri, L. and Sastre, M. (2014) Modulation of Inflammation in Transgenic Models of Alzheimer's Disease. Journal of Neuroinflammation, 11, 25. https://doi.org/10.1186/1742-2094-11-25

[42] Landreth, G.E. and Heneka, M.T. (2001) Anti-Inflammatory Actions of Peroxisome Proliferator-Activated Receptor Gamma Agonists in Alzheimer's Disease. Neurobiology of Aging, 22, 937-944. https://doi.org/10.1016/S0197-4580(01)00296-2 
[43] Kitamura, Y., Shimohama, S., Koike, H., et al. (1999) Increased Expression of Cyclooxygenases and Peroxisome Proliferator-Activated Receptor-Gamma in Alzheimer's Disease Brains. Biochemical and Biophysical Research Communications, 254, 582-586. https://doi.org/10.1006/bbrc.1998.9981

[44] Ricote, M., Huang, J.T., Welch, J.S. and Glass, C.K. (1999) The Peroxisome Proliferator-Activated Receptor (PPARgamma) as a Regulator of Monocyte/Macrophage Function. Journal of Leukocyte Biology, 66, 733-739.

[45] Murphy, G.J. and Holder, J.C. (2000) PPAR-Gamma Agonists: Therapeutic Role in Diabetes, Inflammation and Cancer. Trends in Pharmacological Sciences, 21, 469-474. https://doi.org/10.1016/S0165-6147(00)01559-5

[46] Sastre, M. and Gentleman, S.M. (2010) NSAIDs: How They Work and Their Prospects as Therapeutics in Alzheimer's Disease. Frontiers in Aging Neuroscience, 2 , 20.

[47] Mosconi, L., Pupi, A. and De Leon, M.J. (2008) Brain Glucose Hypometabolism and Oxidative Stress in Preclinical Alzheimer's Disease. Annals of the New York Academy of Sciences, 1147, 180-195. https://doi.org/10.1196/annals.1427.007

[48] Kim, B. and Feldman, E.L. (2015) Insulin Resistance as a Key Link for the Increased Risk of Cognitive Impairment in the Metabolic Syndrome. Experimental \& Molecular Medicine, 47, e149. https://doi.org/10.1038/emm.2015.3

[49] Craft, S. (2005) Insulin Resistance Syndrome and Alzheimer's Disease: Age- and Obesity-Related Effects on Memory, Amyloid, and Inflammation. Neurobiology of Aging, 26, 65-69. https://doi.org/10.1016/j.neurobiolaging.2005.08.021

[50] de la Monte, S.M. (2009) Insulin Resistance and Alzheimer's Disease. BMB Reports, 42, 475-481. https://doi.org/10.5483/BMBRep.2009.42.8.475

[51] Takashima, A. (2006) GSK-3 Is Essential in the Pathogenesis of Alzheimer's Disease. Journal of Alzheimer's Disease, 9, 309-317. https://doi.org/10.3233/JAD-2006-9S335

[52] Cai, Z., Xiao, M., Chang, L. and Yan, L.J. (2015) Role of Insulin Resistance in Alzheimer's Disease. Metabolic Brain Disease, 30, 839-851. https://doi.org/10.1007/s11011-014-9631-3

[53] Son, S.M., Song, H., Byun, J., et al. (2012) Accumulation of Autophagosomes Contributes to Enhanced Amyloidogenic APP Processing under Insulin-Resistant Conditions. Autophagy, 8, 1842-1844. https://doi.org/10.4161/auto.21861

[54] Yu, Y., Li, X., Blanchard, J., et al. (2015) Insulin Sensitizers Improve Learning and Attenuate Tau Hyperphosphorylation and Neuroinflammation in 3xTg-AD Mice. Journal of Neural Transmission (Vienna), 122, 593-606. https://doi.org/10.1007/s00702-014-1294-z

[55] Escribano, L., Simon, A.M., Gimeno, E., et al. (2010) Rosiglitazone Rescues Memory Impairment in Alzheimer's Transgenic Mice: Mechanisms Involving a Reduced Amyloid and Tau Pathology. Neuropsychopharmacology, 35, 1593-1604. https://doi.org/10.1038/npp.2010.32

[56] Abbatecola, A.M., Lattanzio, F., Molinari, A.M., et al. (2010) Rosiglitazone and Cognitive Stability in Older Individuals with Type 2 Diabetes and Mild Cognitive Impairment. Diabetes Care, 33, 1706-1711. https://doi.org/10.2337/dc09-2030

[57] Fei, L., Yong-Jun, H., Zhang-Min, M., et al. (2015) Rosiglitazone Attenuates Memory Impairment in Aged Rat with Diabetes by Inhibiting NF-Kappa B Signal Pathway Activation. Experimental and Clinical Endocrinology \& Diabetes, 123, 536-542. https://doi.org/10.1055/s-0035-1559607 
[58] Watson, G.S., Cholerton, B.A., Reger, M.A., et al. (2005) Preserved Cognition in Patients with Early Alzheimer Disease and Amnestic Mild Cognitive Impairment during Treatment with Rosiglitazone: A Preliminary Study. The American Journal of Geriatric Psychiatry, 13, 950-958.

[59] Sato, T., Hanyu, H., Hirao, K., Kanetaka, H., Sakurai, H. and Iwamoto, T. (2011) Efficacy of PPAR-Gamma Agonist Pioglitazone in Mild Alzheimer Disease. Neurobiology of Aging, 32, 1626-1633. https://doi.org/10.1016/j.neurobiolaging.2009.10.009

[60] Geldmacher, D.S., Fritsch, T., McClendon, M.J. and Landreth, G. (2011) A Randomized Pilot Clinical Trial of the Safety of Pioglitazone in Treatment of Patients with Alzheimer Disease. Archives of Neurology, 68, 45-50. https://doi.org/10.1001/archneurol.2010.229

[61] Feingold, K.R., Grunfeld, C., Heuer, J.G., et al. (2012) FGF21 Is Increased by Inflammatory Stimuli and Protects Leptin-Deficient $o b / o b$ Mice from the Toxicity of Sepsis. Endocrinology, 153, 2689-2700. https://doi.org/10.1210/en.2011-1496

[62] Fisher, F.M. and Maratos-Flier, E. (2016) Understanding the Physiology of FGF21. Annual Review of Physiology, 78, 223-241. https://doi.org/10.1146/annurev-physiol-021115-105339

[63] Sa-Nguanmoo, P., Chattipakorn, N. and Chattipakorn, S.C. (2016) Potential Roles of Fibroblast Growth Factor 21 in the Brain. Metabolic Brain Disease, 31, 239-248. https://doi.org/10.1007/s11011-015-9789-3

[64] Kharitonenkov, A. (2009) FGFs and Metabolism. Current Opinion in Pharmacolo$g y$, 9, 805-810. https://doi.org/10.1016/j.coph.2009.07.001

[65] Ogawa, Y., Kurosu, H., Yamamoto, M., et al. (2007) $\beta$ Klotho Is Required for Metabolic Activity of Fibroblast Growth Factor 21. Proceedings of the National Academy of Sciences of the United States of America, 104, 7432-7437. https://doi.org/10.1073/pnas.0701600104

[66] Adams, A.C., Cheng, C.C., Coskun, T. and Kharitonenkov, A. (2012) FGF21 Requires Betaklotho to Act in Vivo. PLoS ONE, 7, e49977.

https://doi.org/10.1371/journal.pone.0049977

[67] Ge, H., Baribault, H., Vonderfecht, S., et al. (2012) Characterization of a FGF19 Variant with Altered Receptor Specificity Revealed a Central Role for FGFR1c in the Regulation of Glucose Metabolism. PLoS ONE, 7, e33603. https://doi.org/10.1371/journal.pone.0033603

[68] Yang, C., Jin, C., Li, X., Wang, F., McKeehan, W.L. and Luo, Y. (2012) Differential Specificity of Endocrine FGF19 and FGF21 to FGFR1 and FGFR4 in Complex with KLB. PLoS ONE, 7, e33870. https://doi.org/10.1371/journal.pone.0033870

[69] Tomiyama, K., Maeda, R., Urakawa, I., et al. (2010) Relevant Use of Klotho in FGF19 Subfamily Signaling System in Vivo. Proceedings of the National Academy of Sciences of the United States of America, 107, 1666-1671. https://doi.org/10.1073/pnas.0913986107

[70] Makela, J., Tselykh, T.V., Maiorana, F., et al. (2014) Fibroblast Growth Factor-21 Enhances Mitochondrial Functions and Increases the Activity of PGC-1Alpha in Human Dopaminergic Neurons via Sirtuin-1. SpringerPlus, 3, 2.

https://doi.org/10.1186/2193-1801-3-2

[71] Leng, Y., Wang, Z., Tsai, L.K., et al. (2015) FGF-21, a Novel Metabolic Regulator, Has a Robust Neuroprotective Role and Is Markedly Elevated in Neurons by Mood Stabilizers. Molecular Psychiatry, 20, 215-223. https://doi.org/10.1038/mp.2013.192

[72] Tan, B.K., Hallschmid, M., Adya, R., Kern, W., Lehnert, H. and Randeva, H.S. (2011) Fibroblast Growth Factor 21 (FGF21) in Human Cerebrospinal Fluid: Rela- 
tionship with Plasma FGF21 and Body Adiposity. Diabetes, 60, 2758-2762. https://doi.org/10.2337/db11-0672

[73] Hsuchou, H., Pan, W. and Kastin, A.J. (2007) The Fasting Polypeptide FGF21 Can Enter Brain from Blood. Peptides, 28, 2382-2386. https://doi.org/10.1016/j.peptides.2007.10.007

[74] Liang, Q., Zhong, L., Zhang, J., et al. (2014) FGF21 Maintains Glucose Homeostasis by Mediating the Cross Talk between Liver and Brain during Prolonged Fasting. Diabetes, 63, 4064-4075. https://doi.org/10.2337/db14-0541

[75] Bookout, A.L., de Groot, M.H., Owen, B.M., et al. (2013) FGF21 Regulates Metabolism and Circadian Behavior by Acting on the Nervous System. Nature Medicine, 19, 1147-1152. https://doi.org/10.1038/nm.3249

[76] Fon Tacer, K., Bookout, A.L., Ding, X., et al. (2010) Research Resource: Comprehensive Expression Atlas of the Fibroblast Growth Factor System in Adult Mouse. Molecular Endocrinology, 24, 2050-2064. https://doi.org/10.1210/me.2010-0142

[77] Chau, M.D., Gao, J., Yang, Q., Wu, Z. and Gromada, J. (2010) Fibroblast Growth Factor 21 Regulates Energy Metabolism by Activating the AMPK-SIRT1-PGC-1Alpha Pathway. Proceedings of the National Academy of Sciences of the United States of America, 107, 12553-12558. https://doi.org/10.1073/pnas.1006962107

[78] Ye, D., Wang, Y., Li, H., et al. (2014) Fibroblast Growth Factor 21 Protects against Acetaminophen-Induced Hepatotoxicity by Potentiating Peroxisome Proliferator-Activated Receptor Coactivator Protein-1Alpha-Mediated Antioxidant Capacity in Mice. Hepatology, 60, 977-989. https://doi.org/10.1002/hep.27060

[79] Fisher, F.M., Kleiner, S., Douris, N., et al. (2012) FGF21 Regulates PGC-1Alpha and Browning of White Adipose Tissues in Adaptive Thermogenesis. Genes \& Development, 26, 271-281. https://doi.org/10.1101/gad.177857.111

[80] Potthoff, M.J., Inagaki, T., Satapati, S., et al. (2009) FGF21 Induces PGC-1Alpha and Regulates Carbohydrate and Fatty Acid Metabolism during the Adaptive Starvation Response. Proceedings of the National Academy of Sciences of the United States of America, 106, 10853-10858. https://doi.org/10.1073/pnas.0904187106

[81] Katsouri, L., Blondrath, K. and Sastre, M. (2012) Peroxisome Proliferator-Activated Receptor-Gamma Cofactors in Neurodegeneration. IUBMB Life, 64, 958-964. https://doi.org/10.1002/iub.1097

[82] Austin, S. and St-Pierre, J. (2012) PGC1Alpha and Mitochondrial Metabolism-Emerging Concepts and Relevance in Ageing and Neurodegenerative Disorders. Journal of Cell Science, 125, 4963-4971. https://doi.org/10.1242/jcs.113662

[83] Qin, W., Haroutunian, V., Katsel, P., et al. (2009) PGC-1Alpha Expression Decreases in the Alzheimer Disease Brain as a Function of Dementia. Archives of Neurolo$g y$, 66, 352-361. https://doi.org/10.1001/archneurol.2008.588

[84] Katsouri, L., Parr, C., Bogdanovic, N., Willem, M. and Sastre, M. (2011) PPAR $\gamma$ Co-Activator-1 $\alpha$ (PGC-1 $\alpha$ ) Reduces Amyloid- $\beta$ Generation through a PPAR $\gamma$ Dependent Mechanism. Journal of Alzheimer's Disease, 25, 151-162.

[85] Katsouri, L., Lim, Y.M., Blondrath, K., et al. (2016) PPAR $\gamma$-Coactivator-1 $\alpha$ Gene Transfer Reduces Neuronal Loss and Amyloid- $\beta$ generation by Reducing $\beta$-Secretase in an Alzheimer's Disease Model. Proceedings of the National Academy of Sciences of the United States of America, 113, 12292-12297. https://doi.org/10.1073/pnas.1606171113

[86] Planavila, A., Redondo, I., Hondares, E., et al. (2013) Fibroblast Growth Factor 21 Protects against Cardiac Hypertrophy in Mice. Nature Communications, 4, Article No. 2019. https://doi.org/10.1038/ncomms3019 
[87] Planavila, A., Redondo-Angulo, I., Ribas, F., et al. (2015) Fibroblast Growth Factor 21 Protects the Heart from Oxidative Stress. Cardiovascular Research, 106, 19-31. https://doi.org/10.1093/cvr/cvu263

[88] Yu, Y., Bai, F., Wang, W., et al. (2015) Fibroblast Growth Factor 21 Protects Mouse Brain against D-Galactose Induced Aging via Suppression of Oxidative Stress Response and Advanced Glycation end Products Formation. Pharmacology, Biochemistry and Behavior, 133, 122-131. https://doi.org/10.1016/j.pbb.2015.03.020

[89] Breitner, J.C. (1996) The Role of Anti-Inflammatory Drugs in the Prevention and Treatment of Alzheimer's Disease. Annual Review of Medicine, 47, 401-411. https://doi.org/10.1146/annurev.med.47.1.401

[90] Akiyama, H., Barger, S., Barnum, S., et al. (2000) Inflammation and Alzheimer's Disease. Neurobiology of Aging, 21, 383-421. https://doi.org/10.1016/S0197-4580(00)00124-X

[91] Heneka, M.T. and O’Banion, M.K. (2007) Inflammatory Processes in Alzheimer's Disease. Journal of Neuroimmunology, 184, 69-91. https://doi.org/10.1016/j.jneuroim.2006.11.017

[92] Kim, H.W., Lee, J.E., Cha, J.J., et al. (2013) Fibroblast Growth Factor 21 Improves Insulin Resistance and Ameliorates Renal Injury in $d b / d b$ Mice. Endocrinology, 154, 3366-3376. https://doi.org/10.1210/en.2012-2276

[93] Yu, Y., He, J., Li, S., et al. (2016) Fibroblast Growth Factor 21 (FGF21) Inhibits Macrophage-Mediated Inflammation by Activating Nrf2 and Suppressing the NF- $\kappa \mathrm{B}$ Signaling Pathway. International Immunopharmacology, 38, 144-152. https://doi.org/10.1016/j.intimp.2016.05.026

[94] Xu, J., Lloyd, D.J., Hale, C., et al. (2009) Fibroblast Growth Factor 21 Reverses Hepatic Steatosis, Increases Energy Expenditure, and Improves Insulin Sensitivity in Diet-Induced Obese Mice. Diabetes, 58, 250-259. https://doi.org/10.2337/db08-0392

[95] So, W.Y., Cheng, Q., Xu, A., Lam, K.S. and Leung, P.S. (2015) Loss of Fibroblast Growth Factor 21 Action Induces Insulin Resistance, Pancreatic Islet Hyperplasia and Dysfunction in Mice. Cell Death \& Disease, 6, e1707. https://doi.org/10.1038/cddis.2015.80

[96] Sarruf, D.A., Thaler, J.P., Morton, G.J., et al. (2010) Fibroblast Growth Factor 21 Action in the Brain Increases Energy Expenditure and Insulin Sensitivity in Obese Rats. Diabetes, 59, 1817-1824. https://doi.org/10.2337/db09-1878

[97] Qing, Y., Yang, J. and Wan, C. (2015) Increased Serum Fibroblast Growth Factor 21 Levels in Patients with Schizophrenia. Australian and New Zealand Journal of Psychiatry, 49, 849-850. https://doi.org/10.1177/0004867415575380

[98] Inagaki, T., Dutchak, P., Zhao, G., et al. (2007) Endocrine Regulation of the Fasting Response by PPAR $\alpha$-Mediated Induction of Fibroblast Growth Factor 21. Cell Metabolism, 5, 415-425. https://doi.org/10.1016/j.cmet.2007.05.003 


\section{Abbreviations}

$\begin{array}{ll}\text { A } \beta & \text { amyloid- } \beta \\ \text { AD } & \text { Alzheimer's disease } \\ \text { APOE4 } & \text { apolipoprotein E4 } \\ \text { APP } & \text { amyloid precursor protein } \\ \text { APR } & \text { acute phase response } \\ \text { BACE1 } & \beta \text {-APP cleaving enzyme } \\ \text { CNS } & \text { central nervous system } \\ \text { FGF21 } & \text { fibroblast growth factor 21 } \\ \text { FGFR } & \text { fibroblast growth factor receptor } \\ \text { hPGC-1 } \alpha & \text { human PGC-1 } \alpha \\ \text { IL-6 } & \text { interleukin-6 } \\ \text { KLB } & \beta \text {-klotho } \\ \text { LPS } & \text { lipopolysaccharide } \\ \text { MCI } & \text { mild cognitive impairment } \\ \text { MCP-1 } & \text { monocyte chemoattractant protein-1 } \\ \text { MRI } & \text { magnetic resonance imaging } \\ \text { Nrf2 } & \text { nuclear transcription factor-E2-related factor } 2 \\ \text { NSAIDs } & \text { non-steroidal anti-inflammatory drugs } \\ \text { PS1/2 } & \text { presenilins } 1 \text { and } 2 \\ \text { PGC-1 } \alpha & \text { peroxisome proliferator-activated receptor } \gamma \text { coactivator-1 } \alpha \\ \text { PPAR } \gamma & \text { peroxisome proliferator-activated receptor } \gamma \\ \text { PPARs } & \text { peroxisome proliferator-activated receptors } \\ \text { ROS } & \text { reactive oxygen species } \\ \text { Sod2 } & \text { superoxide dismutase-2 } \\ \text { TgFgf21 } & \text { transgenic overexpression of FGF21 mice } \\ \text { TNF- } \alpha & \text { tumor necrosis factor- } \alpha \\ \text { Ucp2/Ucp3 } & \text { uncoupling proteins2/3 } \\ & \end{array}$

